\title{
ОСОБЕННОСТИ УПРАВЛЕНИЯ ИНВЕСТИЦИОННЫМИ РИСКАМИ В СТРОИТЕЛЬСТВЕ НКР
}

\author{
К. э. н., Анюсела Алешаевна Барсегян \\ Республика Армения, Арц̧ах, Шуиинский технологический Университет, лектор кафедрь \\ экономики и управления
}

DOI: https://doi.org/10.31435/rsglobal_ijite/30092019/6665

\section{ARTICLE INFO}

Received 22 July 2019

Accepted 13 September 2019

Published 30 September 2019

\section{KEYWORDS}

construction, investment projects, investment risks, risk factors, risk classification, risk assessment, risk management, profit. \begin{abstract}
Recent structural changes in the economy of the Nagorno-Karabakh Republic have had a significant impact on the entire public relations system, obliging to review the mechanisms for making economic decisions as primary ones. The formation of NKR coincided with the collapse of the USSR and with the radical changes in the system of economic relations that led to this. Since its formation, local authorities have adopted a strategy for the development of the construction sector by stimulating investment, which intends the creation of a favorable investment environment and the development of an appropriate infrastructure.

Despite the fact that NKR construction sector has great potential for attracting investments, the level of foreign investors' activity in this area is quite low. The main reason is probably a high risk level, which is determined by such factors as political instability in the region, the geographical location of NKR, its economic isolation, an incomplete legal framework, and the underdevelopment of financial and market infrastructures. As a result, many investment projects, including cost-effective and efficient ones, are not implemented.

Uncertainty associated with the possibility of adverse situations and consequences during the implementation of the project is characterized by the concept of "risk". The effectiveness of the risk management organization is largely determined by the classification of risk. Depending on the main cause of the risk (basic or natural risk), the classification of risks associated with the implementation of investment construction projects provides a favorable basis for a clear and reasonable risk assessment, which is one of the crucial factors in the effectiveness of the risk management process.
\end{abstract}

Citation: Anjela Barsaghyan. (2019) Peculiarities of Investment Risk Management in the Construction Sector of NKR. International Journal of Innovative Technologies in Economy. 5(25). doi: 10.31435/rsglobal_ijite/30092019/6665

Copyright: (C) 2019 Anjela Barsaghyan. This is an open-access article distributed under the terms of the Creative Commons Attribution License (CC BY). The use, distribution or reproduction in other forums is permitted, provided the original author(s) or licensor are credited and that the original publication in this journal is cited, in accordance with accepted academic practice. No use, distribution or reproduction is permitted which does not comply with these terms.

Введение. Недавние структурные изменения в экономике Нагорно-Карабахской Республики оказали значительное влияние на всю систему связей с общественностью, сделав необходимость пересмотра механизмов принятия экономических решений приоритетом. Из-за растущей неопределенности в экономической среде во всем мире и растущей нестабильности экономической ситуации НКР в фирмы, в том числе занимающиеся экономической деятельностью в строительной отрасли, работают в условиях повышенного риска.

Образование НКР совпало с распадом СССР и радикальными изменениями в системе экономических отношений, которые привели к этому. Республики бывшего СССР были вынуждены перейти от командной системы управления к свободным рыночным отношениям, что потребовало разработки принципиально новых подходов и механизмов управления экономикой. Приоритет был 
отдан разработке систем управления рисками в соответствии с текущей экономической ситуацией и выявлению возможностей их применения, которым не уделялось большого внимания в советское время из-за особенностей механизма действия плановой экономики.

Со времени образования НКР местные власти приняли стратегию развития строительного сектора путем стимулирования инвестиций, что подразумевает создание благоприятной инвестиционной среды и развитие соответствующей инфраструктуры. Последние являются основными условиями для привлечения инвестиций, обеспечивая основу для долгосрочного устойчивого экономического роста.

Согласно официальным данным, строительный сектор НКР составляет около $65 \%$ экономики, что является объективной закономерностью, поскольку необходимо восстанавливать здания и сооружения, поврежденные во время Освободительной войны, строить новые, реконструировать и модернизировать оборонные сооружения. Начиная с 2003 года в различных регионах НКР реализуются разработанные и планированные градостроительные программы.

Несмотря на то, что строительный сектор НКР обладает огромным потенциалом для привлечения инвестиций, уровень активности иностранных инвесторов в этой сфере довольно низок. Основной причиной, вероятно, является высокий уровень риска, который обусловлен как политической нестабильностью в регионе, так и географическим положением НКР и экономической изоляцией НКР, неполной правовой базой, а также неразвитостью финансовой и рыночной инфраструктур. В результате многие инвестиционные проекты, в том числе экономически выгодные и эффективные, не реализуются.

В последние годы были проведены масштабные реформы в сфере строительства НКР. Механизмы государственного управления были коренным образом трансформированы из системы административного управления в государственное регулирование инвестиционной деятельности.

Результаты исследования. Неопределенность, связанная с возможностью возникновения в ходе реализации проекта неблагоприятных ситуаций и последствий, характеризуется понятием «риск» [7]. Эффективность организации управления риском во многом определяется классификацией риска. В зависимости от основной причины возникновения рисков (базисный или природный риск) классификация рисков, связанных с реализацией проектов инвестиционного строительства, обеспечивает благоприятную основу для четкой и обоснованной оценки рисков, что является одним из решающих факторов эффективности процесса управления рисками.

В строительном секторе важно синтезировать группировку рисков в соответствии с такими характеристиками, как направление воздействия на динамику опасности, величина потенциальных потерь. Поэтому выделяется следующий подход (таблица 1.).

Таблица 1. Синтезированная классификация рисков инвестиционного строительства

\begin{tabular}{|c|c|c|c|c|}
\hline \multicolumn{5}{|c|}{ Типы риска } \\
\hline \multicolumn{3}{|c|}{ Повышение уровня риска (истребители) } & \multicolumn{2}{|c|}{ Снижение уровня риска (стабилизирующие) } \\
\hline \multicolumn{2}{|c|}{ Общий риск потерь } & $\begin{array}{l}\text { Частичный } \\
\text { риск потери }\end{array}$ & $\begin{array}{l}\text { Снижение } \\
\text { чувствительности к } \\
\text { риску }\end{array}$ & Исключение риска \\
\hline \multicolumn{2}{|c|}{ Постоянный (постепенный) } & $\begin{array}{l}\text { Дискретный } \\
\text { (мгновенная) }\end{array}$ & \multicolumn{2}{|c|}{$\begin{array}{l}\text { Смешанный } \\
\text { (продолжающийся по частям) }\end{array}$} \\
\hline Финансовый & $\begin{array}{l}\text { Промыш- } \\
\text { ленные }\end{array}$ & Маркетинговая & Ресурсная & $\begin{array}{l}\text { Управление } \\
\text { решениями }\end{array}$ \\
\hline $\begin{array}{l}\text { Климатичес- } \\
\text { кие и эколо- } \\
\text { гические }\end{array}$ & $\begin{array}{l}\text { Производ- } \\
\text { ственные }\end{array}$ & Экономический & $\begin{array}{l}\text { Социально- } \\
\text { демографические }\end{array}$ & $\begin{array}{l}\text { Политический, } \\
\text { геополитический и } \\
\text { правовой }\end{array}$ \\
\hline
\end{tabular}

В условиях высокой степени неопределенности более детальная и точная классификация строительных рисков позволяет разрабатывать и осуществлять более эффективную политику управления инвестиционными рисками. В результате вероятность как потерь, так и банкротства значительно снижается, что существенно повышает стабильность фирмы и формирует деловую репутацию. 
Управление рисками включает разработку и реализацию мер предосторожности, что делает тщательный анализ и группировку факторов риска объективной необходимостью. Принимая во внимание тот факт, что ситуации риска в строительном секторе очень разнообразны и причины их возникновения различны, необходимо рассмотреть факторы риска в контексте разделения общих черт, сгруппировав их вместе.

При определении условий для создания компании и эффективности инвестиционных проектов использование инвестиционных ресурсов особенно важно для классификации факторов на управляемые, неконтролируемые (трудно управляемые) и неуправляемые группы. Многие факторы, которые являются внешними ограничениями деятельности строительной компании на уровне органов государственной власти, рассматриваются как контролируемые факторы, такие как налоговые ставки.

В последние годы неуклонно возрастала важность управления рисками в НКР. По словам О. Кондинской, управление рисками - это способность внедрять подходы, процессы и меры в экономической деятельности, которые позволяют прогнозировать определенные ситуации или явления, связанные с риском, и снижать их влияние посредством вмешательства со стороны руководства [3].

В целом можно сказать, что управление рисками должно обеспечивать гарантированный относительно стабильный уровень прибыли, а не определенное снижение прибыли. Этот стабильный уровень будет максимальным, учитывая условие страхования от возможных потерь. Управление рисками не имеет готового рецепта для каждой ситуации, но оно ясно дает понять, что успеха можно достичь с помощью соответствующих методов и техник для решения экономических проблем.

Однако из-за того, что экономика НКР все еще находится в процессе формирования, производственные риски являются более важными в рамках управления рисками. Провозглашение НКР и возрождение экономики, в центре внимания которой было строительство, стало важным стимулом как для экономической деятельности, так и для исследовательских проектов по управлению инвестициями.

В результате динамичного развития экономики рано или поздно инвесторы в НКР столкиваются с проблемами управления финансовыми и рыночными рисками. В контексте последнего, для управления рисками в международной практике широко используются инструменты математического моделирования, эффективность которых во многом зависит от надежности и полноты входных данных.

Любая инвестиционная деятельность призвана содействовать достижению главной цели экономического развития страны, в то время как заинтересованность инвестора связаны не с макроэкономическим развитием, а с ожиданием прибыли. В этом случае инвестиционные риски являются основными как на микроуровне, так и на макроуровне.

В НКР тоже прежде всего, они связаны с характеристиками макроэкономической ситуации: неэффективностью вертикальной координации, существованием бюрократических механизмов, отсутствием единой информационной системы по тарифам и затратам на строительство, низким уровнем экологии продукта и, в конечном счете, межсекторальными инвестиционными проектами и инвестиционными проектами в строительстве,

В дополнение к этим макроэкономическим проблемам существует также ряд микроэкономических проблем. Уровень технического развития некоторых строительных компаний достаточно низок, почти все организации испытывают высокий спрос на средства, процесс обновления основного капитала и другие специфические проблемы для каждой конкретной организации довольно медленные.

В системе этих проблем заметно, что в строительном секторе нет рациональной системы управления инвестиционными рисками. Что касается уровня развития инвестиционной деятельности строительной компании, то ее можно охарактеризовать базовыми условиями привлечения необходимых инвестиционных ресурсов и нейтрализации всех инвестиционных рисков.

На основании приведенных выше определений этих понятий можно утверждать следующую логическую цепочку: ПР<ПМ<ПП, где ПР-объем подрядных работ ПМпроизводственная мощность и ПП-производственный потенциал. 
Фундаментальные управления рисками в строительном секторе должны быть финансовый анализ, анализ времени и убытков, управление и смягчение последствий [10].

Первоначально рискованные ситуации в строительном секторе НКР возникали в основном из-за ошибок исследовательской фазы разработки проекта. Во многих случаях справедливая стоимость реализации проекта значительно превышала оценку, что имело негативные последствия как для инвесторов, строительных компаний, так и для населения. Различные риски, присущие социально-экономической и политической ситуации в НКР, и срочность реагирования на них требуют, прежде всего, новых подходов к управлению рисками, вытекающих из упущений на этапе разработки и учета.

Государство также оказывает определенное влияние на процесс принятия таких решений, как создание благоприятной правовой и институциональной среды для инвестирования. Последнее может стимулировать инвестиции в строительную отрасль за счет снижения вероятности объективных рисков. То есть результаты деятельности строительных компаний, потенциал отрасли и результаты инвестиционной деятельности напрямую зависят от благоприятности инвестиционной политики.

В рыночной экономике подходы к регулированию инвестиционной деятельности в разных странах различны. С сожалением отметим о том, что в целом целенаправленная политика государственного регулирования инвестиционной деятельности в НКР на практике не практикуется, если только это не требуется по крайней мере по двум из следующих причин:

- частный сектор развит слабо, а местный рынок ценных бумаг еще не создан, поэтому необходимо координировать внутренние проблемы;

- промышленная инфраструктура остро нуждается в модернизации, что также требует больших инвестиций.

В настоящее время денежно-кредитная и фискальная политика, осуществляемая в НКР, не может обеспечить благоприятных условий для воспроизводства основных фондов строительных компаний и активизации инвестиционной деятельности. Чрезвычайно высокая доходность спекулятивных операций является одной из основных причин, по которым инвестиционные ресурсы перетекают из реального сектора экономики в финансовый сектор.

Анализ международной инвестиционной практики показывает, что основным источником инвестиций в развитых индустриальных странах являются внутренние ресурсы (прибыль и амортизация), которые могут доходить до 70 процентов при среднем диапазоне 5560 процентов. Доля инвестиций, осуществляемых за счет кредитных средств, колеблется в пределах 35-40\%, тогда как в развивающихся странах она несравнимо выше. В частности, он превышает 60\% в Индии, 91\% в России, 93\% в Армении. Опросы средних и крупных строительных компаний в НКР показывают, что финансирование инвестиционных проектов за счет внутренних источников составляет около 97\% [5].

Такая структура финансирования строительных проектов делает развитие строительного сектора весьма уязвимым, поскольку он сильно зависит от фискальной политики, а любая нестабильность национальной экономики напрямую влияет на процесс принятия решений об использовании внутренних финансовых ресурсов. Государственная инвестиционная политика развития НКР должна основываться на разработке и реализации обширного комплекса мер, направленных на создание благоприятной конкурентной среды. Для этого необходимо предпринять скоординированные действия по совершенствованию подходов и механизмов антимонопольной политики, принять меры по стимулированию развития малого и среднего бизнеса, проводить более мягкую политику амортизации и налогообложения, а также усовершенствовать законодательство о банкротстве и процедуры управления процессами банкротства.

Примечательно, что, в отличие от фондов других отраслей, в строительной отрасли, в составе основных фондов должен иметь более высокий удельный вес активная часть. Это также подтверждается официальными данными, предоставленными статистической службой НКР (таблица 2).

Таблица 2. Структура ключевого фонда по секторам

\begin{tabular}{|l|c|c|}
\hline \multicolumn{1}{|c|}{ Структура основных фондов } & Строительство & Промышленность \\
\hline Активная часть & $65 \%$ & $43 \%$ \\
\hline Здания и сооружения & $25 \%$ & $54.2 \%$ \\
\hline Другое & $10 \%$ & $2.8 \%$ \\
\hline
\end{tabular}


Основные фонды строительных компаний характеризуются их разнообразием и уникальной ролью, которую они играют в формировании конечного результата. Это связано прежде всего с технико-экономическими характеристиками строительного продукта и, в частности, с тем, что продукция этого сектора экономики является стационарной, мобильными являются только средства производства. Следует отметить, что после распада СССР в постсоветских странах возникли проблемы с оценкой основных фондов. В результате переоценок часто использовались различные коэффициенты, что объясняло существенные ценовые различия. В этих условиях, когда отсутствует единый подход, реальная стоимость основных фондов неясна, и инвестиции в основные фонды строительных компаний становятся более рискованными [1].

Необходимо детально анализировать все этапы технологической цепочки строительства для управления инвестиционным риском путем разработки практических методов. К последним относятся проектные, инженерно-геологические и земляные работы, бурение, взрывные работы, каменные работы, утепление, укладка бетона и железобетона, кровля и разделение. Вышеуказанное обосновывает необходимость поэтапного управления инвестиционными рисками в строительном секторе.

Основываясь на анализе, этапов управления инвестиционными рисками в строительном секторе и взаимодействия между различными уровнями целей управления рисками, оценка воздействия всех рисков и подходы к их снижению могут быть представлены на диаграмме (рис. 1).

На диаграмме приведены систематические этапы управления инвестиционными рисками в строительной отрасли. В то же время инвестиционные риски в строительном секторе могут возникать из-за нежелательных изменений как внутри, так и снаружи. В конечном итоге они требуют уточнения эффективности инвестиционного проекта, то есть стоимость инвестиционного проекта должна быть переоценена. Таким образом, предлагаемая методология предполагает моделирование стоимости и продолжительности строительного проекта в зависимости от факторов риска.

По сути, это позволяет получить более точную картину продолжительность и стоимость строительного проекта в рискованных ситуациях, а также разработать оптимальную стратегию минимизации потерь. Таким образом, возникновение риска, связанного с инвестиционной деятельностью строительных компаний, зависит от определенных обстоятельств, что является причиной неопределенности конечного результата. Такими причинами являются отсутствие экономических показателей строительной компании, а также недостаточная осведомленность о внешней и внутренней среде [2].

По мнению аналитиков, строительство классифицируется как относительно нестабильный отрасль экономики. Одна из основных причин заключается в том, что строительные товары не включены в перечень предметов первой необходимости, а сокращение общего спроса значительно снижает спрос на строительство [4]. Основными причинами увеличения инвестиционного риска являются глобализация рынка, интенсивный характер конкуренции, динамичный рост информационных потоков, рост социальной напряженности и неразмеренности в распределении доходов между странами и т. д.

Они приводят не только к увеличению риска, но и открывают новые возможности для управления инвестиционным риском для строительных компаний.

Ни один из субъектов инвестиционного процесса не имеет четкой информации о текущем состоянии и возможных изменениях рынка НКР. В результате многие инвестиционные проекты, даже те, которые являются экономически жизнеспособными и обоснованными, терпят неудачу из-за непредсказуемых факторов. Этому также способствует тот факт, что строительные компании разрабатывают и реализуют свои стратегии в контексте противоречивых социально-экономических преобразований в экономике НКР. 


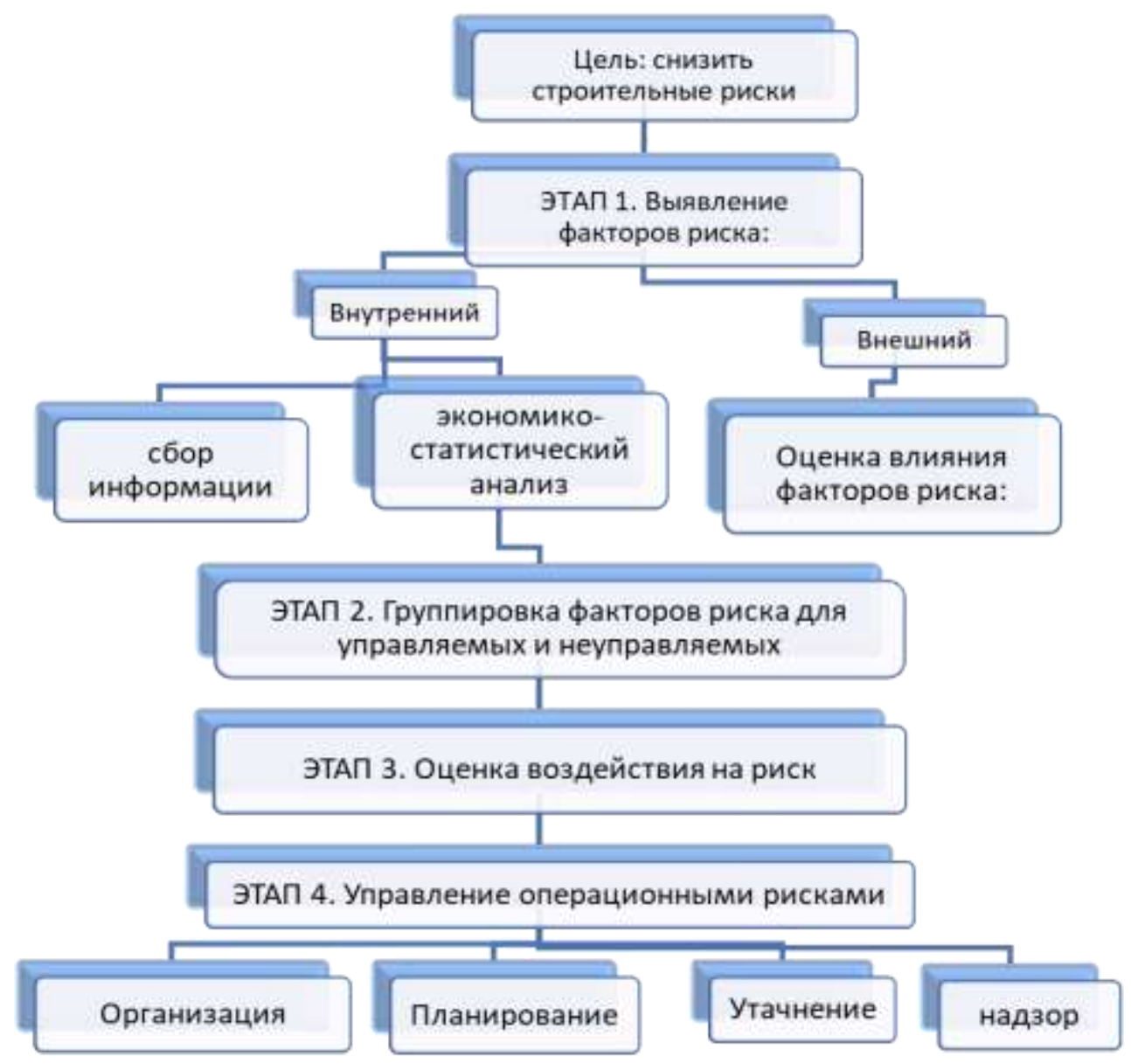

Рис. 1. Системный подход к управлению инвестициионным риском

В связи с особенностями экономического развития НКР, организации в строительного сектора должны принять стратегию динамичного роста социально-экономического потенциала, уделяя при этом пристальное внимание возможностям применения нестандартных управленческих подходов в связи с нежелательными изменениями. Большинство строительных компаний, действующих в НКР, характеризуются иерархической структурой управления. Основным недостатком этих структур является медленный поток информации, который продлевает время для принятия управленческих решений и снижает способность организации реагировать на изменяющуюся среду.

Создание новой, эффективной организационной структуры отнимает много времени, требует больших затрат и ресурсов. Эффективная организационная структура считается эффективной и при минимальных затратах может способствовать полной реализации целей организации.

В настоящее время широко используются матричные организационные структуры, которые эффективны в сложных, быстро меняющихся условиях. Эта структура является гибкой и позволяет быстро реагировать на изменения ситуации на рынке и желаний клиентов. Основным преимуществом матричной структуры является то, что она создает условия для оптимального использования ограниченных ресурсов, в том числе человеческого капитала.

Современные крупные строительные компании могут применять любую организационную структуру управления и полностью реализовывать свой инвестиционный проект. Наиболее перспективной для них является дивизионная организационная структура, которая создается путем создания бизнес-единиц в областях деятельности, что позволяет четко контролировать результаты этой деятельности.

Выводы. Таким образом, можно сделать вывод, что существует четкая связь между размером строительной компании, уровнем диверсификации ее деятельности, организационной формой управления и выбором структуры.

Выбор оптимальной организационной структуры дает нам возможность снизить риски и их потенциальные негативные воздействия, но на практике невозможно полностью избежать рисков. 
Содействие и стимулирование инвестициям в строительные проекты для развития промышленного и строительного потенциала непризнанной республики НКР, не имеющей прямого доступа к мировому рынку, является приоритетом, который позволит ей модернизировать основные фонды, повысить организационно-технический уровень продукции строительных компаний, ускорить темпы экономического роста и обеспечить рост их жизнедеятельности.

Риск недостаточной информации обратно пропорционален степени, в которой предприниматель обладает информацией о внешней среде своей организации. Предприниматель должен иметь четкую информацию о конкурентах, партнерах и особенно поставщиках.

\section{ЛИТЕРАТУРА}

1. Воробьев С.Н. Управление рисками в предпринимательстве. М.: Изд-во «Дашков и Ко». 2006 г.с. 210

2. Доронкина Л.Н., Формирование системы управления рисками в инвестиционно-строительном бизнесе, Издательство "Палеотип"- 2005, 138 стр.

3. Кадинская О. А. Управление финансовыми рисками. М. - 2000. С.

4. Клейнер Г.Б. Предприятие в нестабильной экономической среде: риски, стратегии, безопасность.М., Экономика, 1997, стр.6.

5. Нагорно-Карабахская Республика: Становление государственности на рубеже веков. Институт политических исследований, ГНКО, Ереван, 2009, -37стр.

6. Найт Р.Ф, Притти Д.Дж, Философии риска, стоимость компании и ее руководитель. В сборнике Дж.Пикфорд, Управление рисками, Финанс, М., 2004, с.345-350.

7. Огаджанян С.Г., Тонян В.С. «Экономический риски и его оценка», Информационные технологии и упаравление, - Ереван 2010. - 6, с. 74-80.

8. Проценко О.Д., Цакаев А.Х. Организация риск-менеджмента на современном предприятии // Российское предпринимательство. - 2001. - № 7 (19). — c. 32-38. — URL: http://bgscience.ru/lib/440/.

9. Тер-Саакян Карине, Основные направления проблем и перспектив развития экономики НКР.

10. Шапкин А.С. Экономические и финансовые риски. - М.- 2003

11. Черкасов В.В. Проблемы риска в управленческой деятельности. - М., 2002. С.320.

12. Kaplan, S., and B.J. Garrick, 1981, On the quantitative definition of risk, Risk Analysis1(1): 11-27. Knabb, R.D., J.R. Rhome, and D.P. Brown, 2005. 